\title{
O PRECONCEITO RACIAL OITOCENTISTA NA PRIMEIRA OBRA NATURALISTA DE ALUÍZIO AZEVEDO
}

\author{
Gileno Alves Ferreira* \\ Cleide de Lima Chaves**
}

RESUMO: $\mathrm{O}$ trabalho aqui apresentado objetiva investigar o preconceito racial da sociedade maranhense sobre o personagem principal, Dr. Raimundo, na obra $O$ mulato do abolicionista Aluísio Azevedo. Outrossim, estudar o uso da linguagem em que, preconceituosamente, no século XIX, se submetiam, ao sabor do cientificismo, negros e descendentes. A partir da literatura historiográfica e antropológica sobre o tema do racismo brasileiro, bem como a análise da linguagem empregada no romance, buscou-se analisar tal ocorrência na composição naturalista. Na produção azevediana, que opera eminentemente como crítica social, averiguar determinada prática que perpassa gerações no Brasil e no mundo.

PALAVRAS-CHAVE: Preconceito; $O$ mulato; Naturalismo; Oitocentista.

\section{Introdução}

O presente trabalho tem como objeto o preconceito racial sobre o personagem principal, Dr. Raimundo, na obra O mulato (1881) do abolicionista Aluísio Azevedo. A pesquisa traz uma abordagem acerca do sentimento segregacionista lançado pela sociedade maranhense sobre o jovem mestiço, nascido no Brasil, enviado, desde criança, pelo pai a

\footnotetext{
* Mestrando em Letras: Cultura, Educação e Linguagens pela Universidade Estadual do Sudoeste da Bahia (Uesb).

** Professora Titular da Universidade Estadual do Sudoeste da Bahia (Uesb). Doutora em História Social pela Universidade Federal do Rio de Janeiro (UFRJ).
} 
estudar na Europa, recém-chegado de Portugal, após formar-se em Direito. Assim, apresenta a discriminação racial experienciada por um mulato, culto, filho de mercador português, rico e branco, e de mãe escrava, pobre e negra, de passagem pela cidade de São Luís do Maranhão, para desfazer-se de suas terras, deixadas por seu genitor. O desenrolar do romance evidencia o tratamento social que envolve a vida e a morte deste homem que, planejando instalar-se no Rio de Janeiro e seguir carreira jurídica, obriga-se a incluir em seu projeto de vida sua prima Ana Rosa com quem se apaixona. Por fim, o trabalho foca o posicionamento segregacionista por parte de toda a sociedade, sobretudo da avó da moça, integrante da elite maranhense, que colabora na expulsão do jovem advogado, levando-o à morte.

Objetiva-se, de modo geral, analisar em $O$ mulato, a questão do preconceito sofrido pelo personagem principal Dr. Raimundo, em como ocorre a discriminação que o conduz à morte. De modo específico, objetiva-se abordar acerca do preconceito e discriminação na sociedade ludovicense oitocentista e refletir sobre as diferenças entre grupos e indivíduos naquele contexto social.

Quanto ao diálogo com a bibliografia, o trabalho se norteará com mais de uma linha, a saber, a historiográfica, com a historiadora Lilia Moritz Schwartz, em sua obra O espetáculo das raças; Jean-Yves Mérian, com Aluísio Azevedo: vida e obra (1857-1913); a jornalística, com Josué Montello em Aluísio Azevedo e a polêmica d’O Mulato e a antropológica, com o Dr. Kabengele Munanga, em seu livro Rediscutindo a mestiçagem no Brasil: identidade nacional versus identidade negra, entre outros autores que contribuíram para o debate sobre racismo no Brasil.

Com uma leitura aprofundada da obra, inserida nos seus contextos imediatos, coloca-se, no âmbito do literário, o naturalismo, energizado pelas ciências naturais, pelo positivismo de Auguste Comte, o determinismo e o darwinismo, com a lei da seleção natural, teorias difundidas na segunda metade do século XIX. Assim, o foco é o personagem Raimundo, a partir da compreensão de que o homem é um produto do seu tempo e do seu espaço. 


\section{Um espetáculo entre o negro e o branco no século XIX}

No tocante ao processo de construção sociopolítica, entre os anos de 1870 e 1930 , a partir da tentativa das elites do Brasil de esboçar um projeto de identidade nacional brasileira envolvendo as contribuições do índio, do europeu e do negro africano, importa aqui inicialmente compreender acerca da visão literária de Aluízio de Azevedo. Assim, observar sua relação com a cidade de São Luiz na construção de significado em seu trabalho escrito. Outrossim, refletir sobre o poderio da ciência oitocentista no país, suas estratégias e seu espírito de segregação manifesto pelas teorias ideológicas em disseminação naquele período.

O romance $O$ mulato, do abolicionista Aluísio Azevedo, é uma obra naturalista que marca o início da escola no Brasil. Apesar de ser esta, entre literatos, uma concepção corrente, de acordo com Jean-Yves Mérian (2013, p. 575), "nessa obra de transição, as convicções naturalistas que Aluísio Azevedo manifestava em suas crônicas de jornal não estão presentes com a mesma nitidez. Mas este romance marca a transição entre o romantismo e o naturalismo.”. Entre estes, encontra-se o realismo, em cujo domínio literário, nascialhe, em oposição, nova tendência, a saber, o naturalismo.

Segundo Mérian, São Luís do Maranhão, com respeito a polêmicas relacionadas ao realismo e o naturalismo na literatura, não escaparia à influência dessas concepções literárias. De Portugal, navios traziam as mais recentes publicações de romances em Lisboa e França. Inicialmente, poucos se interessavam por essas novidades. Tinha-se nas obras românticas ainda uma representação local do consumo literário. Jornais vindos do Rio de Janeiro informavam sobre o que vinha acontecendo concernente às novas tendências, em que o termo "realismo" era considerado ultrapassado e o Naturalismo como um conceito que se afirmara com certa contribuição da Revista Brasileira, que se colocava como espaço de debates. Silvio Romero, em todos os números, defendia os naturalistas, enquanto Machado de Assis opunha-se ao novo conceito com artigos e a publicação de sua obra realista 
Memórias póstumas de Brás Cubas. Entrementes, "A difusão das novas ideias na literatura estava ligada a um intenso esforço de propaganda em favor das filosofias determinista, evolucionista e positivista." (MÉRIAN, 2013, p. 177).

N'O mulato narra-se acerca da sociedade são-luisense em que um garoto, Raimundo, aos cinco anos de idade, filho de mercador português rico e branco, José Pedro, e de mãe escrava pobre e negra, Domingas, é enviado pelo pai para estudar na Europa. Nesse ínterim, seu pai, morto pelo padre da comunidade, deixa-lhe sua herdade. Após vinte e um anos, já formado em direito no exterior, o rapaz retorna ao seu país, em São Luís do Maranhão, para desfazer-se de suas terras, deixadas por seu genitor. Raimundo, planejando partir para o Rio de Janeiro e seguir sua carreira jurídica, obriga-se a incluir em seu projeto de vida sua prima Ana Rosa com quem se apaixona ao instalar-se em casa de seu tio Manuel Pescada, irmão de seu pai. A partir de então, o sentimento segregatório por parte de toda a sociedade, sobretudo da avó da moça, D. Maria Bárbara, que integra a elite maranhense, se projeta como uma ideia fixa contra o jovem mestiço. Enreda-se então, em um processo de preconceitos e perversidades, um diabólico plano para impedir que o Dr. Raimundo saiba sobre sua descendência e o que ocorrera com seus pais. Assim, a trama que resulta na morte do jovem advogado por seu concorrente à mão da moça, Luís Dias, empregado de Pescada, tem como mentor o mesmo assassino de seu pai, o Cônego Diogo.

A trama macabra contra Dr. Raimundo se dá quando, de volta à cidade de São Luís, apresentando-se culto, formado no exterior, o jovem advogado, de excelente aparência, vindo pomposamente da Europa, declara estar no lugar apenas de passagem, com pretensões de vender o que herdara de seu pai e iniciar sua carreira de direito na cidade do Rio de Janeiro. Gilberto Freyre utiliza-se do termo "Mulatos cor de rosa”, em sua obra Sobrados e mocambos para chamar atenção sobre a maneira singular com a qual eram tratados certos escravos por seus senhores.

Esses mulatos cor-de-rosa, alguns louros, olhos azuis, podendo passar por brancos em lugares onde não soubessem direito sua origem, não foram raros no Brasil do século XIX. A favor da transferência deles do número dos escravos para o dos livres ou da sua ascensão social, de "pretos" para "brancos", houve sempre poderosa corrente 
de opinião, ou antes, de sentimento. Isto desde o século XVIII. Em 1773 já um alvará del-Rei de Portugal falava de pessoas "tão faltas de sentimento de humanidade e de religião" que guardavam, nas suas casas, escravos mais brancos do que elas, com os nomes de pretos e de negros (FREYRE, 2013. p. 461).

Aluísio Tancredo Gonçalves de Azevedo, nascido no Maranhão a 14 de abril de 1857, muito cedo demonstra a sua vocação no campo das letras. Contudo, “descobrimos também a expressão dos primeiros gostos artísticos de Aluísio Azevedo: a pintura e os arranjos de cenário" (MÉRIAN, 2013, p. 48). Aos 19 anos muda-se para o Rio de Janeiro com o objetivo de aprimorar-se na área de desenho e pintura. Trabalha como caricaturista para jornais e, na Escola de Belas-Artes, estuda durante um ano. Em 1879, retorna ao Maranhão devido ao falecimento de seu pai. Entre os anos de 1880 a 1881, contra os jornais católicos, milita na imprensa de São Luís com A Pacotilha (1880) e O Pensador (1880). Por ser um escritor envolvido com as questões sociopolíticas e desde muito jovem observar em sua cidade, São Luís do Maranhão, a escravidão e o racismo, ainda no ano de 1881, com pouco mais de 20 anos de idade, com seu espírito crítico, publica o seu segundo romance, O mulato, marcando o naturalismo no Brasil.

No final do século XIX, de acordo com o discurso racial fluente no país, as características físicas eram critérios que classificavam o indivíduo em sua descendência racial e, por conseguinte, em seu estrato social. Raimundo teria irrefletidamente aprovada a sua inserção na mais elevada esfera elitista daquela comunidade, pois o seu biótipo seria semelhante aos da gente daquele meio. Azevedo traz à reflexão, conforme Jean-Yves Mérian (2013, p. 248), que, embora o título de sua obra seja "O mulato", seu trabalho não se refere apenas ao destino de um sujeito, mas a toda sociedade ludovicense que neste representa um papel. Antes do personagem principal, um personagem coletivo é apresentado ao leitor, como um espaço de conflito onde ocorre toda a trama. Essa coletividade é o ambiente, que é minuciosamente descrito nos dois primeiros capítulos, compreendendo um sistema de relações que desde sempre atormentara o autor. 
A crítica de ordem social, na urdidura do romance e nos seus elementos intervalares ou acessórios, não se restringe, n'O mulato, ao preconceito de cor e ao clero - estende-se a toda a cidade, naquilo que São Luís então apresentava como susceptível de reparo, principalmente nos tipos, nas tradições e nos costumes (MONTELLO, 1975, P. 50).

Faz-se necessário aqui inicialmente uma abordagem do ponto de vista sociológico em que se lança uma luz sobre o contexto histórico que envolve a produção da obra décadas antes e décadas após a sua publicação. A visão que se tinha do índio, do negro e do mestiço no Brasil do final do século XIX e início do XX é aqui abordada observando o pensamento cientificista internalizado por camadas distintas da sociedade, como destacou a historiadora Lilia Schwarcz (1993).

O Brasil, no século XIX, concernente ao aspecto fenotípico dos seus habitantes, expunha a necessidade de se criar uma identidade nacional. De acordo com Schwarcz (1993) o país, aos olhos dos viajantes que aqui chegavam, seria um laboratório das "raças humanas" e tornara-se o paraíso dos naturalistas. Nomes como Gustave Aimard, Louis Agassiz e o Conde Arthur de Gobineau compartilhavam do entendimento de que não poderia existir em parte alguma o fenômeno da miscigenação. Naturalistas, médicos e juristas, entre si, disputavam posições em suas áreas de atuação que paulatinamente se entrelaçavam na busca por soluções cada vez mais distantes da realidade. Nesse sentido, orientados pelos discursos ideológicos europeus, era consensual a ideia de que a mistura entre indivíduos de origem europeia, "brancos", com negros e/ou índios seria a razão das moléstias e produziria um genótipo irreversivelmente débil e aquém das capacidades físicas e intelectuais da espécie humana.

Segundo a autora (1993), o país dos trópicos era visto como o universo das miscigenações raciais. Do ponto de vista do médico João Batista Lacerda (1846-1915), então diretor do Museu Nacional do Rio de Janeiro, a questão se resolveria embranquecendo a nação, como declara sua tese apresentada ao $1^{\circ}$ Congresso Internacional das Raças, em Londres, do qual foi convidado a participar em julho de 1911. Com título expressamente declarativo "Sur les métis au Brèsil”, "o Brasil mestiço de hoje tem no branqueamento em 
um século sua perspectiva, saída e solução (Lacerda, 1911)", o representante de "um típico país miscigenado" argumenta com positividade. O estudo tinha reproduzido como abertura um quadro de M. Brocos, pintor da Escola de Belas Artes do Rio de Janeiro, com a legenda: "Le nègre passant au blanc, à la troisième generation, par l'effet du croisement des races". Remontava, então, o autor, sob um prisma imagético, além de argumentações, as perspectivas do período, fazendo uma alusão às teorias do branqueamento das populações no Brasil.

Ao longo de um século o Brasil estaria, segundo o que propunha João Batista Lacerda, completamente branco, como representa a imagem da criança no quadro. Destarte, a visão do branqueamento ganha contornos artísticos, marca o período e profetiza um Brasil liberto do considerado como maior de seus males. Logo, se disseminava uma proposta que se esboçava cotidianamente no quadro social com pinceladas positivistas em cuja vontade de verdade se desconhecia oposição à altura, "O positivismo, após dez anos, havia contaminado vários meios sociais: intelectuais, médicos, engenheiros, militares, um setor significativo do que era a elite urbana” (MÉRIAN, 2013, p. 293). Tinha-se, desse modo, através da via artística visual, a "recomendação" de que o negro veria sua prole alcançar o mundo dos brancos. A família representada na obra do pintor mostra-se, sobretudo, pela matriarca negra, agradecida à ciência pelo engenhoso resultado.

De acordo com Schwarcz (1993), importa apresentar uma história da ciência brasileira, de suas ideias e persistências como canalizadora de um processo dinâmico de reconstrução de modelos e conceitos.

[...] interessa compreender como o argumento racial foi política e historicamente construído nesse momento, assim como o conceito raça, que além de sua definição biológica acabou recebendo uma interpretação sobretudo social. O termo raça, antes de aparecer como um conceito fechado, fixo e natural, é entendido como um objeto de conhecimento, cujo significado estará sendo constantemente renegociado e experimentado nesse contexto histórico específico, que tanto investiu em modelos biológicos de análise. $\mathrm{O}$ que se pode dizer é que as elites intelectuais locais não só consumiram esse tipo de literatura, como a adotaram de forma original. (SCHWARCZ, 1993. p. 17-18). 
O conceito raça para o escritor Aluísio Azevedo constitui, no momento em que antecede as suas principais produções, o objeto singular de suas atividades no campo social. Em “O Pensador" (1880) e "Pacotilha" (1880) o difícil combate no enfrentamento aos setores escravagistas ganhou com a obra $O$ mulato, a oportunidade de transmitir um ideário abolicionista, sob o viés da racialidade, na pessoa do mulato Raimundo. Engajado na luta pela abolição da escravatura, Aluísio destaca o ponto central de suas discussões sinalizando para a delimitação do lugar em que se situaria os descendentes dos escravizados no Brasil.

Todavia, com respeito à abolição, segundo Mérian, para Aluísio se constitui como uma necessidade que envolve prioritariamente o crescimento do Brasil rumo à civilização. Os sentimentos cotidianos dos que são oprimidos pela escravidão não são uma preocupação para o escritor, pois suas perspectivas dizem respeito aos brancos. "Neste ponto ele se inscreve perfeitamente na abordagem dos teóricos da abolição segundo a definição de Otávio Ianni.” (MÉRIAN, 2013, p. 284).

Se o abolicionismo foi um fenômeno político aparentemente orientado em benefício dos cativos, e apesar das manifestações exteriores nessa direção, ele foi essencialmente um movimento organizado e liderado pelos cidadãos livres, brancos, mulatos ou negros. No contexto histórico-econômico em que se manifestou, precisa ser considerado um fenômeno "branco", em nome do negro. Lutando pela abolição do trabalho escravizado, os brancos lutavam em benefício dos seus próprios interesses, conforme estavam consubstanciados ou poderiam objetivar-se num sistema econômico-social fundado no trabalho livre. Por isso é que o abolicionismo foi uma revolução "branca", isto é, um movimento político que não se orientava no sentido de transformar, como se afirmava, o escravo em cidadão, mas transfigurar o trabalho escravo em trabalho livre. (IANNI apud MÉRIAN, 2013, p. 284, 285).

De acordo com a historiadora Emília Viotti da Costa, em sua obra "A abolição", nesse período, o trabalho livre seria muito mais interessante do que a mão de obra escrava. 
Ao fazendeiro, as condições tornaram-se favoráveis empregando em suas fazendas trabalhadores livres. Até porque, aumentavam os preços dos escravos, ao passo que mais oneroso se tornava mantê-los cativos.

Pouco a pouco, alguns fazendeiros começaram a perceber que o trabalho livre podia ser mais vantajoso do que o escravo. José Vergueiro, por exemplo, publicava em 1870 um artigo em um jornal de grande circulação em São Paulo, demonstrando que o trabalho dos colonos era mais rendoso do que o dos escravos. Cem escravos, argumentava ele, importam em 200 contos de réis, pelo menos. Com esse capital, seria possível obter trabalhadores livres. Computandose o custo do escravo - as despesas com alimentação, vestuário, assistência médica e juros sobre o capital empatado -, as despesas chegavam, em alguns casos, a ser superiores às correspondentes ao salário de um trabalhador livre. Por que então continuar investindo capitais em escravos? (COSTA, 2008, p. 68).

Estrategicamente, Aluísio propõe, em sua literatura, um mestiço que apresenta todas as suas faculdades em equilíbrio e excelente aptidão física. Ou seja, a representação de um resultado positivo da experiência do cruzamento entre raças humanas chamaria atenção do leitor também para o fato de um descendente de negro tornar-se protagonista no universo literário. De outro modo, quais chances haveria de, por meio da experiência literária, representar a população negra e seus descendentes? As características descritas do Dr. Raimundo exprimem um tipo humano que, apesar de refletir o amálgama considerado criminoso, por ser mestiço, coaduna com a ideia de progresso na aplicação do princípio do branqueamento.

Raimundo tinha vinte e seis anos e seria um tipo acabado de brasileiro se não foram os grandes olhos azuis, que puxara do pai. Cabelos muito pretos, lustrosos e crespos; tez morena e amulatada, mas fina; dentes claros que reluziam sob a negrura do bigode; estatura alta e elegante; pescoço largo, nariz direito e fronte espaçosa. A parte mais característica da sua fisionomia era os olhos - grandes, ramalhudos, cheios de sombras azuis; pestanas eriçadas e negras, pálpebras de um roxo vaporoso e úmido; as sobrancelhas, muito desenhadas no rosto, como a nanquim, faziam sobressair a frescura da epiderme, que, no lugar da barba raspada, lembrava os tons suaves 
e transparentes de uma aquarela sobre papel de arroz. Tinha os gestos bem educados, sóbrios, despidos de pretensão, falava em vOz baixa, distintamente sem armar ao efeito; vestia-se com seriedade e bom gosto; amava as artes, as ciências, a literatura e, um pouco menos, a política. (AZEVEDO, 1964, p. 18).

No que diz respeito à imaginação do autor de $O$ mulato, tem-se que, muito antes dessa produção, havia constante inquietação e insatisfação com a realidade imposta. Com base no que observara ainda muito jovem, em sua cidade natal, um espírito criativo associado à aversão que passara a ter pela covardia dos opressores escravistas, moveram no caricaturista o desejo de lutar em favor dos oprimidos com a sua arte. Aluísio, entre sua infância e adolescência, vira, sendo castigado, um mulato que gemia horrores amarrado a um tronco. Seus pais não possuíam escravos mas, em um sombrio quarto, no convento Nossa Senhora do Carmo, assustado observava o castigo e imaginava o sofrimento daquele ser humano. Subsequentemente, já abraçando a causa abolicionista, no jornal O pensador, o assunto foi tratado pelo viés libertário do então escritor naturalista. A imaginação tornara-se cada vez mais aguçada, não apenas por esse testemunho, mas por todas as vezes que algo do tipo ocorresse ao longo de sua existência.

[...] pela primeira vez considerei minha pátria uma terra miserável; porque consentia, autorizava com uma lei escandalosa, o escravo. Já lá se vão doze anos e o escravo de Nossa Senhora do Carmo está vivo em minha memória como se eu o tivesse visto neste instante. Foi ele quem me despertou a primeira ideia de liberdade, devo talvez a esse desgraçado o grande ódio que voto hoje a tudo que é despótico e opressor (MÉRIAN 1988, p. 48).

Do ponto de vista de Jean-Yves Mérian (1988), O mulato (1881) tem sua produção e publicação embasadas em sentimentos dessa natureza. Nesse ínterim, todo um processo criativo se nutre da imaginação do autor, de sua angústia em conviver com pessoas que lidavam naturalmente com tal prática que jamais lhe desceria à garganta. As injustiças que costumava testemunhar em São Luís do Maranhão se acumularam em sua mente de modo a fornecer-lhe condições de representação no âmbito de suas práticas artísticas como desenhista. Assim que chega ao Rio de Janeiro, onde primeiramente se instalou como artista 
no campo visual, por volta de 1876 a 1878, ocupa-se Aluísio com ilustrações que vão de encontro à mentalidade social imposta pela classe dita "branca, rica e superior".

Aluísio Azevedo apostou numa historicidade comprometida com a reinvenção da nacionalidade do país. De acordo com Jean-Yves Mérian (2013, p. 293, 294), o autor de $O$ Mulato, ao depositar em Raimundo as características europeias como resultado do embranquecimento, expressa sua opinião sobre a mestiçagem como a melhor alternativa à uma evolução civilizacional.

O romance de Aluísio Azevedo não é unicamente um libelo em prol da abolição da escravatura e um panfleto anticlerical, características que apareceram à primeira vista na ocasião de seu lançamento. Aluísio expressa igualmente, nesse livro, com bastante clareza, suas teses sobre a sociedade ideal do futuro: uma república positivista e liberal, que favoreça a integração racial e cultural com a finalidade de atingir uma civilização europeia tropical. O mulato claro, verdadeiro protótipo do homo brasiliensis, é o eixo em torno do qual a democracia racial brasileira deve ser edificada (MÉRIAN, 2013, p. 294).

Com respeito ao índio, por meio de literatos como Domingos José Gonçalves de Magalhães e Gonçalves Dias, tinha-se a contribuição do romantismo, utilizando o indianismo como tema de uma nova concepção literária do "escritor de missão", colocando o poeta como emissário de verdades e de nobres sentimentos. Já o negro, ainda carecia de quem o viesse, de algum modo, representar.

Em 1891, circulava o primeiro número da Revista Acadêmica da Faculdade de Direito do Recife. Suas metas eram estimular a produção científica, criar laços amistosos entre intelectuais nacionais e estrangeiros e fortalecer as faculdades de Direito no país. Seu primeiro artigo é propor "um quadro evolutivo para o direito", estabelecendo a frequente presença, pelos seus trinta primeiros anos, de autores como Haeckel, Darwin, Le Bon, Lombroso e Ferri. Estes dois últimos, destacados por estudos na área criminológica, entendiam o crime sob a análise do indivíduo em seu tipo físico e sua raça de pertencimento. Adversos à ideia de livre arbítrio, acreditavam em um regimento do universo por uma ordenação mecânica causal e evolutiva que não permitia a liberdade ao indivíduo. Este seria 
o resultado de suas características físicas na formação de sua raça, como resultante de uma correlação com o meio. Destarte, o fenótipo passa a ser visto como um chamado "espelho d'alma”, onde se refletem vícios e virtudes.

\begin{abstract}
Para alguns teóricos, o tipo físico do criminoso era tão previsível que seria possível delimitá-lo de forma objetiva. Lombroso, por exemplo, criou uma minuciosa tabela, subdividida em: "elementos anathomicos" (assimetria cranial e facial, região occipital predominante sobre a frontal, fortes arcadas superciliares e mandíbulas além do prognatismo); "elementos physiológicos" (insensibilidade, invulnerabilidade, mancinismo e ambidestria); "elementos psycologicos" (tato embotado, olfato e paladar obtusos, visão e audição ora fracas ora fortes, falta de atividades e de inibição); e "elementos sociológicos" (existência de tatuagens pelo corpo) (RAFDR, 1913:68, apud SCHWARSCZ, 1983, p. 166).
\end{abstract}

Vale ressaltar que desde o século XVIII, com a classificação cromática de Moreau de Sain-Mary, mencionado mais à frente, classificar e categorizar o sujeito do ponto de vista racial, constituir-se-ia o caminho mais eficaz para um convencimento mais abrangente das teorias deterministas. Assim, houve até quem opinasse, indicando determinadas categorias de criminosos: ladrões, assassinos e violentos. E, como se não bastasse, certo professor de direito criminal, Laurindo Leão, chega a reunir em lista loucos, segundo a sua teoria, de diversos tipos, entre a genialidade e a criminalidade:

São semi loucos: Julio Cesar, Napoleão, Flaubert, Richelieu, Dostoiewsky, Byron, Pascal, Mozart e Wagner. São loucos (ao menos no fim da vida) Comte, Newton, Nietche, Moliere. São maníacos perseguidos: Rousseau, Haller. São maniacos de grandeza Balzac, Swift. São neurasthenicos Voltaire, Chateaubriand, Zola, Chopin e sobretudo Pasteur. Além de outras formas de maniacos: original, Tolstoi; esquecido, Diderot; decadente, Wagner; surdo, Bethoven; sonnambulo, Goethe; egoísta, Victor Hugo... O que preocupa é menos a insanidade manifesta e mais a proximidade existente entre a degeneração, a loucura e a criminalidade (RAFDR, 1913:58-9, apud SCHWARSCZ, 1983, p. 166).

Mesmo alguns anos após a morte do autor de $O$ mulato, as teorias do determinismo e do social-darwinismo se manifestavam como solução para o país em suas várias facetas, 
conservando todo o seu rigor. No caso da criminalidade, o supracitado "método antropológico", como um critério objetivo de análise, era para esses homens de ciência um conjunto de certezas sobre o indivíduo e também sobre a nação, como já afirmava Laurindo: “Uma nação mestiça é uma nação invadida por criminosos” (RAFDR, 1919:54, apud SCHWARSCZ, 1993, p. 167).

Segundo o antropólogo Kabengele Munanga, à luz do discurso pluriculturalista, o objetivo com o qual se desdobra o preconceito aqui tratado é fruto não apenas de questões biológicas, mas sociais, pois a forma física do segregado em nada corresponde com o tipo de rejeição assumido por seus segregadores. De acordo com uma classificação cromática realizada por um estudioso referido por Kabengele Munanga em sua pesquisa, Moreau de Saint-Méry, em tradição oral e documentos escritos da época, baseada em suas observações pessoais, compara-se o personagem Raimundo com o último da lista que se segue:

Sacatra: 8 a 16 partes brancas e 112 a 120 partes negras; Griffe: 24 a 32 partes brancas e 96 a 104 partes negras; Marabou: 40 a 48 partes brancas e 80 a 88 partes negras; Mulâtre: 56 a 70 partes brancas e 58 a 72 partes negras; Quarteron: 71 a 96 partes brancas e 32 a 57 partes negras; Métis: 104 a 112 partes brancas e 16 a 24 partes negras; Mamelouc: 116 a 120 partes brancas e 8 a 12 partes negras; Quarteronné: 122 a 124 partes brancas e 4 a 6 partes negras; Sang mêlé: 125 a 127 partes brancas e 1 a 3 partes negras. (Munanga, 1999, p. $37-$ 38).

\section{O preconceito racial expresso pelo uso da língua}

Ainda que muitas vezes de modo sutil, todos os tipos de cerceamento dos direitos dos menos privilegiados e todas as injustiças decorrentes da vontade de verdade das classes dominantes se configuram como um modelo elaborado de colonização que se perpetua com o uso apropriado da língua, beneficiando um grupo e prejudicando outro. Do ponto de vista da Linguística proposta por Kanavillil Rajagopalan (2003), no sentido de amenizar os efeitos indesejáveis dessa realidade, os linguistas necessariamente devem 
proporcionar maior acesso às suas atividades no tocante ao estudo da língua, com a discussão a respeito da linguagem como um direito do cidadão.

No tocante ao estudo de termos pejorativamente empregados nos tratamentos pessoais, nota-se, na linguagem observada, nas expressões daquela que parece ser a que mais repudia o jovem mestiço, a saber, D. Maria Bárbara, a maior contribuição para com o processo segregatício. O termo "cabra", por ela proferido, sempre que se dirige à pessoa de Raimundo, de uso frequente no Norte do Brasil, designativo do mestiço de negro e mulato, é, pois, visto de forma depreciativa.

Alguns entendem “cabra”. como quarteirão de mulato com negro, mulato escuro, ou caboclo escuro, preponderando tratar-se de mestiço de branco e negra, resultando, assim, em "mulato”, como se confere à origem de Raimundo. Também, diz-se do cruzamento de índio e africano, inferior aos elementos que o formam, e pior do que o caboclo e o negro. É o "cabra" indivíduo forte, petulante, de instintos ruins, sanguinário, bastante diferente do mulato propriamente dito, pois àquele lhe falta, em relação a este, inteligência e boas maneiras. Toma-se como o mestiço cuja dosagem do sangue inferior é maior. Do ponto de vista de Moreau de Saint-Méry, citado por Kabengele Munanga (1999) que na época categorizou os fenótipos humanos em nove classificações cromáticas, o "cabra” seria o Sacatra, com 8 a 16 partes brancas e 112 a 120 partes negras, o primeiro da lista do negro para o branco. Comparado a "bode e cabrito", cabra, pelo segregador, torna-se inferior em relação a "mulato", proveniente de "mula", animal hibrido, resultante do cruzamento entre animais de espécies diferentes, a égua e o jumento, explicitado pelo cientificismo da época como incapaz de reproduzir-se, estéril.

A partir de ocorrências de falas na obra, localizou-se o aparecimento dos termos "mulato" e "cabra". Vale ressaltar que em todo trabalho escrito da referida narrativa, o termo "mulato" somam 25 vezes e "cabra" 26 vezes, o que pode-se inferir que os termos mais pejorativos - como o de cabra - foram mais utilizados para reforçar a tese do autor acerca do preconceito racial sofrido pelo personagem principal, dr. Raimundo. 
O uso da língua, extrapolando sua função básica de estabelecer interação comunicacional, aqui, pela elite escravocrata maranhense, que reduz a condição humana aos limítrofes do vulgar animalesco, atinge alguém cuja formação educacional proposta pelo autor do romance confere atribuições não vistas em seus segregadores. A maneira com a qual não apenas Dona Maria Bárbara, mas os demais mencionados no enredo, tratam o advogado mestiço recém-chegado da Europa exprime repulsa, desdém e excessivo ódio. Desse modo, deixa transparecer um sentimento que engloba os limites das questões raciais.

No imaginário popular da época se refletiu, a partir das inferências propostas pela elite, uma visão equivocada do jovem jurista que desconhecia completamente sua ascendência e consequentemente sua situação no contexto social. Influenciada pela imagem deturpada que fizeram os familiares e amigos da moça, as pessoas, muitos até mulatos de visível mistura, teceram comentários maldosos, configurando uma linguagem que veicula o ódio e o desejo cobiçoso dos algozes morais do segregado.

Por onde seguiam, Raimundo ia levantando a atenção de todos. As negrinhas corriam ao interior das casas, chamando em gritos a sinhámoça para ver passar "Um moço bonito!" Na rua, os linguarudos paravam com ar estúpido, para examiná-lo bem; os olhares mediamno grosseiramente da cabeça aos pés, como em desafio; interrompiam-se as conversas dos grupos que ele encontrava na calçada. Quem é aquele sujeito, que ali vai de roupa clara e um chapéu de palha? - Or'essa! Pois ainda não sabes? respondia um Bento. É o hóspede de Manuel Pescada! - Ah! este é que é o tal doutor de Coimbra? - O cujo! Afirmava o Bento. — Mas Brito, vem cá! disse o outro, com grande mistério, como quem faz uma revelação importante. - Ouvi dizer que é mulato!... E a voz do Brito tinha o assombro de uma denúncia de crime. - Que queres, meu Bento? São assim estes pomadas cá da terra dos papagaios! E ainda se zangam quando queremos limpar-lhes a raça, sem cobrar nada por isso! - Branquinho nacional! (AZEVEDO, 1964. p. 59-60).

Com relação ao preconceito racial observado na produção da narrativa, tem-se como característico da escola a zoomorfização, sendo o sujeito humano concebido como fruto do sistema biológico. Do autor, então, pode-se, por meio do excerto abaixo, inferir tal ideia positivista. Os termos "sem-vergonha", "malvado", "patife", "desavergonhado" e 
similares proferidos por D. Maria Bárbara manifesta o desprezo exacerbado da escravocrata e "macaco" a expressão utilizada por Aluísio naturalmente por cumprimento à maneira materialista de observação.

Foi interrompido por Benedito que, nu da cintura para cima e acossado pela velha Bárbara, atravessou a sala com agilidade de macaco. As senhoras espantaram-se, mas abriram logo em gargalhadas. O moleque alcançara a porta da escada e fugira. Então, o Dias, que até aí se conservara quieto no seu canto, ergueu-se de um pulo e deitou a correr atrás dele. Desapareceram ambos. Benedito era cria de Maria Bárbara; um pretinho seco, retinto, muito levado dos diabos; pernas compridas, beiços enormes, dentes branquíssimos. Quebrava muita louça e fugia de casa constantemente. A velha estacara no meio da sala furiosa.

— Ai, gentes! não reparem!... bradou. Aquele não-sei-que-diga, aquele maldito moleque!... Pois o desavergonhado não queria vir trazer água na sala, sem pôr uma camisa?... Patife! Ah, se o pego!... Mas deixa estar, que não as perdes, malvado! E correndo à janela: — Se seu Dias não te alcançar, tens amanhã um campeche te seguindo a pista, sem-vergonha! (AZEVEDO. 1881 p. 35).

Percebe-se que quem segrega nesses moldes o faz com o desejo profundo de reduzir a uma dimensão ainda maior, sobretudo, mais perversamente, no caso de Raimundo que, analisado segundo o que se percebe na obra, poderia ser melhor equiparado ao Sangmêlé: 125 a 127 partes brancas e 1 a 3 partes negras, último da lista de Saint-Méry que entrando em sua oitava e última instância poderia ser o resultado da mistura de 8.191 partes brancas com apenas uma parte negra. O mulato Raimundo, aqui referido, fenotipicamente, apresentava-se como alguém longe de ser tomado como escravo, com traços de homem europeu, pele clara e olhos azuis.

\section{Considerações finais}

Conclui-se que refletir sobre as diferenças entre grupos e indivíduos no contexto sociopolítico do Brasil, no século XIX, em pesquisa sobre o preconceito racial na obra azevediana, constitui aqui uma oportunidade de compreensão acerca do pensamento oitocentista no que tange a abolição e suas concepções; o cientificismo e suas estratégias; o 
posicionamento do autor de $O$ mulato e sua devoção pelo positivismo; e, especialmente, no tocante ao recorte da obra, como objeto do referido estudo, o ressentimento social do povo maranhense.

\title{
THE OITOCENTIST RACIAL PRECONCEPTION IN THE FIRST NATURALIST WORK BY ALUÍZIO AZEVEDO
}

\begin{abstract}
The paper presented here aims to investigate the racial prejudice of the Maranhão society about the main character, Dr. Raimundo, in the work The mulatto of the abolitionist Aluísio Azevedo. Also, to study the use of language in which, in the nineteenth century, prejudiced, under the influence of scientism, blacks and descendants. From the work The spectacle of the races of the historian Lilia Moritz Schwartz and studies of the anthropologist Kabengele Munanga, among others, analyze such occurrence in the naturalistic composition. In the Azorean production, which operates eminently as social critique, to ascertain a certain practice that goes through generations in Brazil and in the world.
\end{abstract}

KEYWORDS: Preconception; The mulatto; Naturalism; Eighteenth century.

\section{REFERÊNCIAS}

AZEVEDO, Aluísio. O mulato. São Paulo: Martins, 1964.

COSTA, Emília Viotti da. A abolição. $8^{a}$ ed. rev. E ampl. - São Paulo: Editora UNESP, 2008.

FREYRE, Gilberto. Sobrados e mucambos: introdução à história da sociedade patriarcal no Brasil - 2. 1. ed., digital. São Paulo, 2013.

IANNI, Otávio. As metamorfoses do escravo. São Paulo: Difusão Europeia do Livro, 1962.

MONTELlo, J. Aluísio Azevedo e a polêmica d'O Mulato. Rio de Janeiro: Livraria José

Olympio Editora S.A., 1975.

MÉRIAN, Jean-Yves. Aluísio Azevedo: vida e obra (1857-1913). Rio de Janeiro: Fundação Biblioteca Nacional: Garamond, 2013.

- Aluísio Azevedo: vida e obra (1857-1913). Rio de Janeiro: Espaço e

tempo/Banco Sudameris-Brasil; Brasília: INL, 1988. 
MUNANGA, Kabengele. Rediscutindo a mestiçagem no Brasil: identidade nacional versus identidade negra. Petrópolis, RJ: Vozes, 1999.

RAJAGOPALAN, Kanavillil, Por uma linguística crítica: linguagem, identidade e a questão ética. São Paulo: Parábola Editorial, 2003.

SCHWARCZ, Lilia Moritz. O Espetáculo das Raças - cientistas, instituições e questão racial no Brasil 1870-1930. São Paulo: Companhia das Letras, 1993.

Recebido em: 06/09/2018.

Aprovado em: 17/12/2018. 